\title{
Using shear wave elasticity in normal terminal ileum of a healthy southwest Chinese population: a pilot study of reference elasticity ranges
}

\author{
Jie-Ying Zhao $^{1 \# \wedge}$, Xin Gao ${ }^{2 \#}$, Hua Zhuang ${ }^{1 \wedge}$, Yu-Ting Wu ${ }^{1 \wedge}$, Yuan Luo ${ }^{1 \wedge}$, Ji-Gang Jing ${ }^{1}$, Yan Zhang ${ }^{2}$ \\ ${ }^{1}$ Department of Ultrasound, West China Hospital of Sichuan University, Chengdu, China; ${ }^{2}$ Department of Gastroenterology, West China Hospital \\ of Sichuan University, Chengdu, China
}

\#These authors contributed equally to this work as co-first authors.

Correspondence to: Hua Zhuang, MD, PhD. Department of Ultrasound, West China Hospital of Sichuan University, 37\#Guo Xue Xiang, Chengdu 610041, China. Email: annzhuang@yeah.net.

\begin{abstract}
Background: Elastography has not been widely applied to the gastrointestinal tract. The bowel wall's normal elasticity values are still unknown and are necessary for studies of gastrointestinal diseases. This study explores the feasibility of using shear wave elastography (SWE) to measure the terminal ileum wall stiffness in healthy subjects and establish the corresponding normal ranges of elasticity values.

Methods: This observational study recruited 139 healthy adult volunteers from April to July 2020. All examinations were performed in the anterior terminal ileum wall. Shear wave velocity (SWV) and Young's modulus (E) values were measured in the midline on longitudinal sections and replicated different operators' obtained data. Also, bowel wall thickness (BWT) and depth were recorded. Subgroups were classified according to the volunteers' gender, age, body mass index (BMI), BWT, and depth. The intra-class correlation coefficient was calculated to analyze inter- and intra-operator consistency, and independent t-tests and one-way analysis of variance were used to explore the differences in variables.

Results: The inter- and intra-operator agreements were good to excellent by different operators and in the replicated measurements (intra-operator consistency: 0.963; inter-operator consistency: 0.842). In all volunteers, the mean SWV was $1.08 \pm 0.25 \mathrm{~m} / \mathrm{s}$, the mean E value was $3.84 \pm 1.84 \mathrm{kPa}$, and the median $\mathrm{BWT}$ was $2 \mathrm{~mm}$. SWV and $\mathrm{E}$ did not show significant differences according to gender $(\mathrm{P}=0.589)$, age $(\mathrm{P}=0.738)$, $\mathrm{BMI}(\mathrm{P}=0.678)$, depth $(\mathrm{P}=0.375)$, or $\mathrm{BWT}(\mathrm{P}=0.410)$. BWT did not show significant differences according to age $(\mathrm{P}=0.142)$, BMI $(\mathrm{P}=0.863)$, or depth $(\mathrm{P}=0.368)$.

Conclusions: SWE can be used in terminal ileum wall stiffness measurements with good reliability, and the SWE values do not appear to vary significantly according to different physiological factors. The corresponding elasticity ranges of the terminal ileum in normal adults were acquired.
\end{abstract}

Keywords: Shear wave elastography (SWE); terminal ileum (TI); reference ranges; shear wave velocity (SWV); Young's modulus; inflammatory bowel disease (IBD)

Submitted Jul 16, 2020. Accepted for publication Feb 15, 2020.

doi: 10.21037/qims-20-877

View this article at: http://dx.doi.org/10.21037/qims-20-877

^ ORCID: Jie-Ying Zhao, 0000-0002-6262-7592; Hua Zhuang, 0000-0003-3395-1921; Yu-Ting Wu, 0000-0002-4889-4598; Yuan Luo, 0000-0002-8882-7904. 


\section{Introduction}

Elastography is an ultrasound (US)-based imaging technology that objectively assesses tissue stiffness. It was first described by Ophir et al. in 1991 (1) and is regarded as an extension of conventional US (2). It introduces a mechanical excitation and monitors the resulting tissue response, exerting a comparable effect to that of palpation but with increased spatial discrimination and objectivity $(3,4)$. Therefore, it is valuable for differential diagnosis since tissue stiffness changes are often involved in various diseases $(3,5)$.

Elastography mainly comprises two different approaches: strain elastography and shear wave elastography (SWE). Of these, SWE can measure the quantitative information of elasticity recorded as specific data (SWV/E) $(3,5)$. The SWE application was developed more recently than strain elastography, especially regarding the gastrointestinal (GI) tract $(2,6)$.

Initially, SWE was widely used to evaluate and characterize liver, breast, and thyroid diseases (7-9). It was first used in GI diseases in 2013 by Dillman et al. (10), who conducted a Crohn's disease animal model. Several studies have reported the value of using SWE, especially in inflammatory bowel disease (IBD) and rectal neoplasms (10-19). For instance, it has proven effective in the differentiation of fibrotic from inflammatory strictures in Crohn's disease $(14,18)$ and in assessing and staging rectal tumors $(12,13,15)$. However, there are only a few studies of SWE involving healthy subjects, especially trans-abdominally (20), and the normal elasticity values of the bowel wall measured by SWE remain uncertain (18,21-25).

The terminal ileum (TI) is the most commonly involved site of various diseases in the small intestine and has a comparatively stationary anatomic location (20). Additionally, the thickness of other bowel wall usually ranges from 1 to $2 \mathrm{~mm}$ (26), whereas the TI may be slightly thicker (27). This makes the TI preferable for elasticity measurements because it is less influenced by peristalsis and is more suitable for the placement of regions of interest (ROI). This study aims to explore the feasibility of using SWE to measure the TI wall elasticity in healthy subjects and to establish the corresponding normal reference ranges.

\section{Methods}

This observational study was approved by the ethics committee on the biomedical research of the West China
Hospital of Sichuan University (no. 359, 2020), and written informed consent was obtained from all subjects. Subjects were included if they were aged $18-70$ years and had no known diseases or history of digestive, cardiovascular, or immune system disorders. Exclusion criteria were any imaging, laboratory evidence, or history of the disease in the systems above, pregnancy or lactation, or age under 18 or over 70 years (Figure 1). In total, 139 healthy adult volunteers (mostly students and workers in the hospital and their relatives) were enrolled from April to July 2020. Besides demographic data such as gender, age, height, weight, and BMI, BWT and the depth of the anterior TI wall were also recorded. Subgroups were classified according to the volunteers' gender, age, BMI, BWT, and depth.

\section{Conventional US and elasticity data acquisition}

Conventional US and SWE were performed using the Acuson Sequoia system (Siemens, Erlangen, Germany) with a 4-10 MHz 10L4 linear transducer, a general abdomen preset, and $8 \mathrm{~cm} / \mathrm{s}$ set for the Color Doppler scale (as default). The two operators had over 5 years' experience in GI tract US. All volunteers had fasted for over 8 hours and were placed in the supine position to relax the abdomen. To avoid intraluminal gas interference, all data were obtained from the anterior TI wall, with moderate compression. The echo beam was always perpendicular to the abdominal wall. The probe was initially placed vertically to the ascending colon's long axis section, then moved downwards to the ileocecal valve level to reach the TI. The measurements were performed in the midline on longitudinal sections of the TI (Figure 2), within $5 \mathrm{~cm}$ of the ileocecal valve.

In the conventional US images, depth and BWT were measured (Figure 3, A and B), and bowel vascularization was observed (Figure 2). The vascularity grading protocol of 0-IV referred by Limberg et al. in 1999 (28) was used as follows: $0=$ normal BWT; $\mathrm{I}=\mathrm{a}$ thickened bowel wall without a color Doppler signal; II = a few, short signals; III $=$ long intramural perfusion signals; $\mathrm{IV}=$ intramural and mesentery signals. SWE was performed to measure the TI wall stiffness. The bowel wall consists of five distinct sonographic layers when examined with a mid-high frequency probe: starting from the lumen, the hyperechoic layer 1 corresponds to the interface between the mucosa and the lumen. The hypoechoic layer 2 corresponds to the mucosa. The hyperechoic layer 3 corresponds to the submucosa, including the interface between the submucosa 


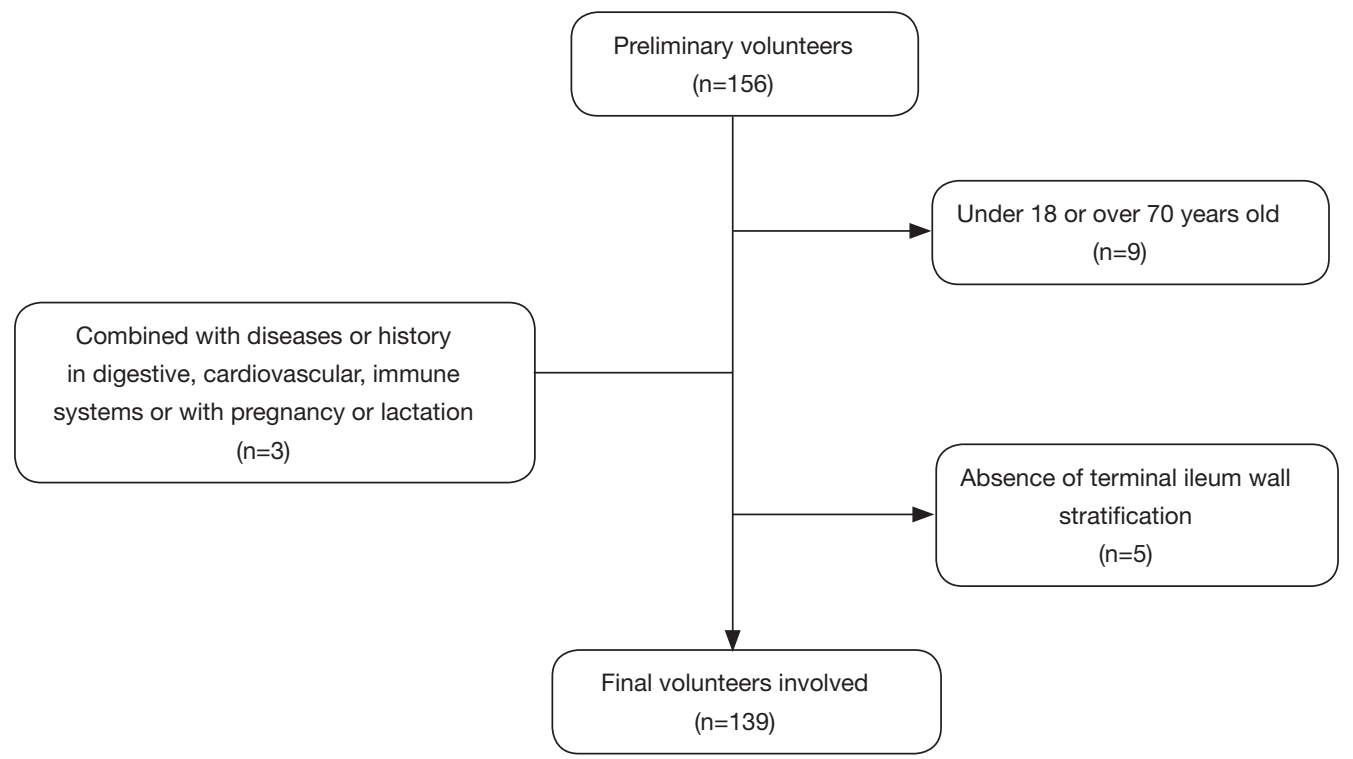

Figure 1 Volunteers' recruitment flowchart.

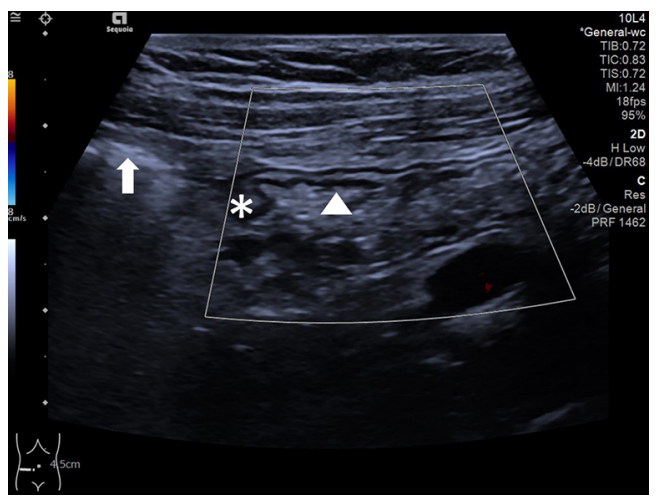

Figure 2 The longitudinal section of the TI. The blood flow signals of the TI wall are not observed (Limberg score 0). Arrow: cecum; asterisk: ileocecal valve; arrowhead: anterior wall of TI. TI, terminal ileum.

and mucosa. The hypoechoic layer 4 corresponds to most of the proper muscle. And layer 5 corresponds to the hyperechoic interface echo between the proper muscle and the serosa (20). BWT was measured from the mucosa interface and the lumen, to the interface between the serosa and proper muscle $(20,29)$ (Figure 3B).

The ROI was placed in the SWE mode to cover the whole anterior TI wall for 3-5 consecutive samplings to obtain the E and SWV values (Figure 4). The ROI diameter was determined by the rounding value of the BWT of the anterior TI wall, from the interface between the mucosa and the lumen to the interface between the serosa and proper muscle. The ROI placements were not overlapped, and we placed five ROIs when applicable. If the proximal TI wall was too thin to set the ROI, or the section was not ideal, three measurements were taken instead of five. The median of the 3-5 measurements was selected as the representative value. Then another row of 3-5 measurements and the median selection was repeated by the same operator (operator 1). The measurements were taken while volunteers held their breath. Each volunteer underwent two replicated measurements, both in the longitudinal section, by operator 1 (Figure $4 A$ ). SWV values were reported in meters per second $(\mathrm{m} / \mathrm{s})$ and $\mathrm{E}$ in kilopascals $(\mathrm{kPa})$.

Meanwhile, some volunteers were randomly chosen to be examined by operator 2 (Figure 4B), who was blinded to the results of operator 1 . The parameters were measured in the midline on longitudinal sections as previously described. Due to workforce and time constraints, we chose 20 volunteers and collected their data to calculate interoperator consistency. Additionally, the data of all volunteers obtained by operator 1 on two separate occasions were compared to calculate intra-operator consistency. Since the $\mathrm{E}$ value comes from $\mathrm{SWV}(\mathrm{c}): \mathrm{E}=3 \rho \mathrm{c}^{2}$ (where $\rho$ is a constant representing the soft tissue density) (3), the interand intra-operator consistencies were calculated only for the SWV values. 

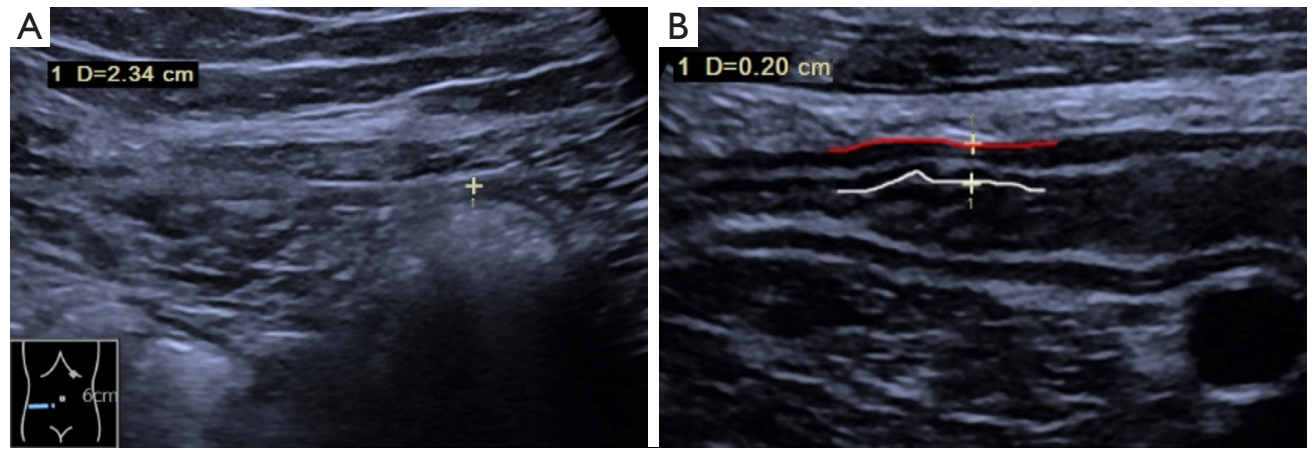

Figure 3 Measurement of depth and BWT. All measurements were performed in the anterior wall of the TI. (A) Depth measurement, between skin and serosa. (B) BWT measurement, from the interface between the mucosa and the lumen (white line), to the interface between the serosa and proper muscle (red line). BWT, bowel wall thickness; TI, terminal ileum.
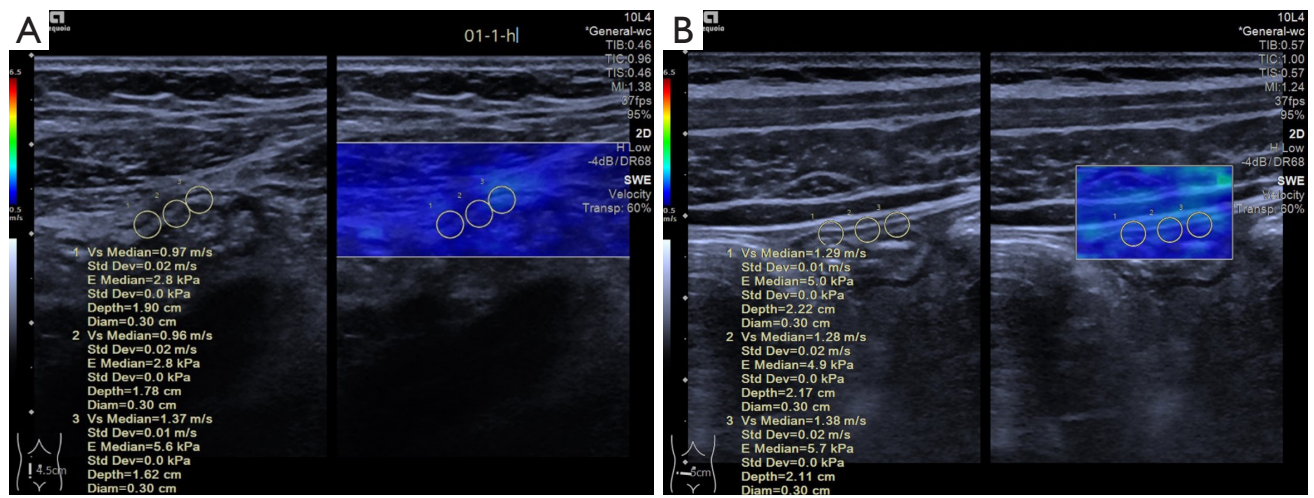

Figure 4 Measurement of SWE values of the TI by different operators. (A) Dual-picture of SWV and E measurements by operator 1. (B) Dual-picture of SWV and E measurements by operator 2. SWE, shear wave elastography; TI, terminal ileum; SWV, shear wave velocity; E, Young's modulus.

\section{Statistical analysis}

The Statistical Package for the Social Sciences (version 19.0.0, IBM SPSS Statistics, Armonk, NY, USA) was used for all statistical analyses. From the results of previous studies, the mean and standard deviation for SWE values and a permissible error $(\delta)$ of 0.2 were used to calculate a sample size of 123 subjects (139 in actual) to achieve $95 \%$ confidence (one-sided). An independent $t$-test was used for the analysis of continuous variables. One-way analysis of variance was used for SWV and E among subgroups of age, BMI, depth, and BWT. Normally distributed data were described as the mean \pm standard deviation plus range, and non-normal data (height, weight, and BWT) were described as the median plus range. The intra-class correlation coefficient (ICC) and 95\% confidence interval
(CI) were calculated to evaluate the inter- and intra-group data reliability. Probability values $<0.05$ were considered statistically significant.

\section{Results}

\section{Volunteer information}

According to the exclusion criteria, 17 volunteers were excluded (Figure 1). In total, 139 healthy volunteers were included ( 41 men, 98 women) with an age range of 18-68 years (mean: $39.72 \pm 12.06$ years), height range of $1.45-1.81 \mathrm{~m}$ (median height: $1.60 \mathrm{~m}$ ), weight range of $42-87 \mathrm{~kg}$ (median weight: $58 \mathrm{~kg}$ ), and a BMI range of $15.8-33.3 \mathrm{~kg} / \mathrm{m}^{2}$, (mean BMI: $22.53 \pm 3.01 \mathrm{~kg} / \mathrm{m}^{2}$ ) (Table 1). The TI wall stratification existed in all volunteers. 
Table 1 Overall characteristics of the healthy volunteers

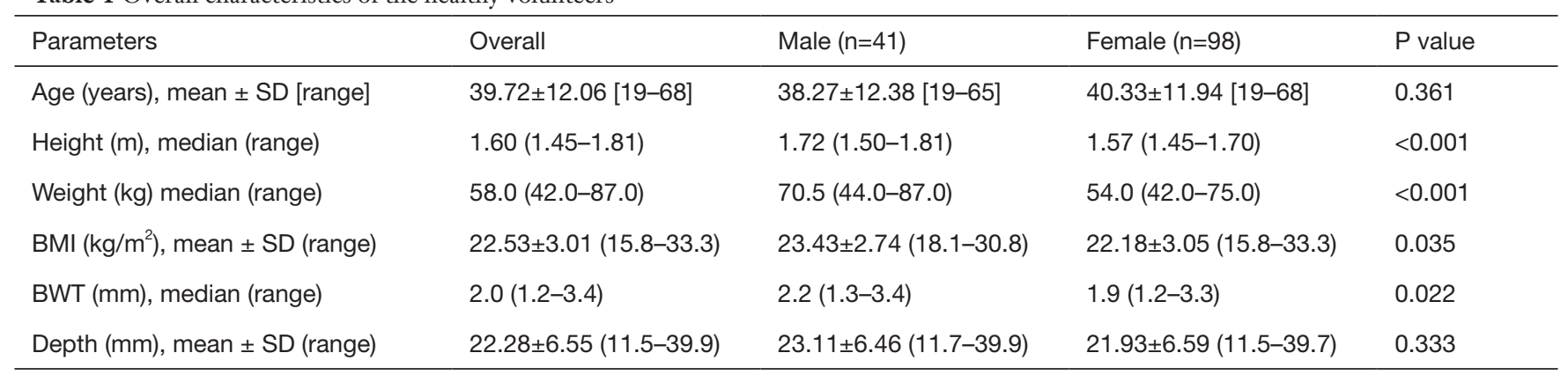

The $\mathrm{P}$ value represents differences in gender. BMI, body mass index; BWT, bowel wall thickness; SD, standard deviation.

Table 2 Inter- and intra-operator consistency of SWV values measurements

\begin{tabular}{lll}
\hline Consistency & SWV $(\mathrm{m} / \mathrm{s})$ & $\mathrm{ICC}(95 \% \mathrm{Cl})$ \\
\hline Intra-operator consistency $(\mathrm{n}=139)$ & $1.02 \pm 0.18$ & $0.963(0.947-0.975)$ \\
First time & $1.01 \pm 0.20$ & \\
Second time & $1.03 \pm 0.22$ & $0.842(0.576-0.941)$ \\
Inter-operator consistency $(\mathrm{n}=20)$ & $1.12 \pm 0.20$ & \\
\hline
\end{tabular}

SWV, shear wave velocity; ICC, intra-class correlation coefficient; Cl, confidence interval.

According to the measurement protocol of Limberg's scoring system (28), no pathological increase of blood flow was detected, indicating a normal TI wall in all volunteers.

For the total number of volunteers, the mean value of SWV was $1.08 \pm 0.25 \mathrm{~m} / \mathrm{s}$ (range, $0.6-2.11 \mathrm{~m} / \mathrm{s}$ ), E was $3.84 \pm 1.84 \mathrm{kPa}$ (range, $1.1-13.4 \mathrm{kPa}$ ), and the depth was $22.28 \pm 6.55 \mathrm{~mm}(11.5-39.9 \mathrm{~mm})$. The median of the BWT was $2.0 \mathrm{~mm}(1.2-3.4 \mathrm{~mm})$.

\section{Reliability of SWV measurements}

Data from 20 volunteers were used to calculate the interand intra-operator consistencies of the SWV measurements. The mean SWV values measured by the different operators were $1.02 \pm 0.18 \mathrm{~m} / \mathrm{s}$ (operator 1 ) and $1.12 \pm 0.20 \mathrm{~m} / \mathrm{s}$ (operator 2). The inter-operator agreement was good and the corresponding ICC was 0.842 (95\% CI: 0.576-0.941) (Table 2). The mean SWV values measured by operator 1 were $1.01 \pm 0.20 \mathrm{~m} / \mathrm{s}$ (the first occasion) and $1.03 \pm 0.22 \mathrm{~m} / \mathrm{s}$ (the second occasion). The intra-operator agreement was excellent and the corresponding ICC was 0.963 (95\% CI: 0.947-0.975) (Table 2).

\section{Elasticity parameters in different subgroups}

SWV and E were evaluated in different subgroups (Table 3). SWV and $\mathrm{E}$ did not show any significant differences with gender $(\mathrm{P}=0.589)$, age $(\mathrm{P}=0.738)$, $\mathrm{BMI}(\mathrm{P}=0.678)$, depth $(\mathrm{P}=0.375)$, or BWT $(\mathrm{P}=0.410)$. The mean $\mathrm{SWV}$ and $\mathrm{E}$ of the different subgroups are shown in Table 3.

\section{BWT in different subgroups}

The BWT of the TI did not show any significant differences with age $(\mathrm{P}=0.142), \mathrm{BMI}(\mathrm{P}=0.863)$, or depth of the anterior wall $(\mathrm{P}=0.368)$ (Table 4). The gender difference in BWT was significant. It was greater in males (range, 1.3-2.4 mm; median: $2.2 \mathrm{~mm}$ ) than in females (range, $1.2-3.3 \mathrm{~mm}$; median: $1.9 \mathrm{~mm})(\mathrm{P}=0.022)$ (Table 1). The median BWT of the TI in the different subgroups is shown in Tables 1,4.

\section{Discussion}

The small intestine remains challenging to examine due to its anatomic and morphological characteristics. 
Table $3 \mathrm{SWV}$ and E values in different subgroups

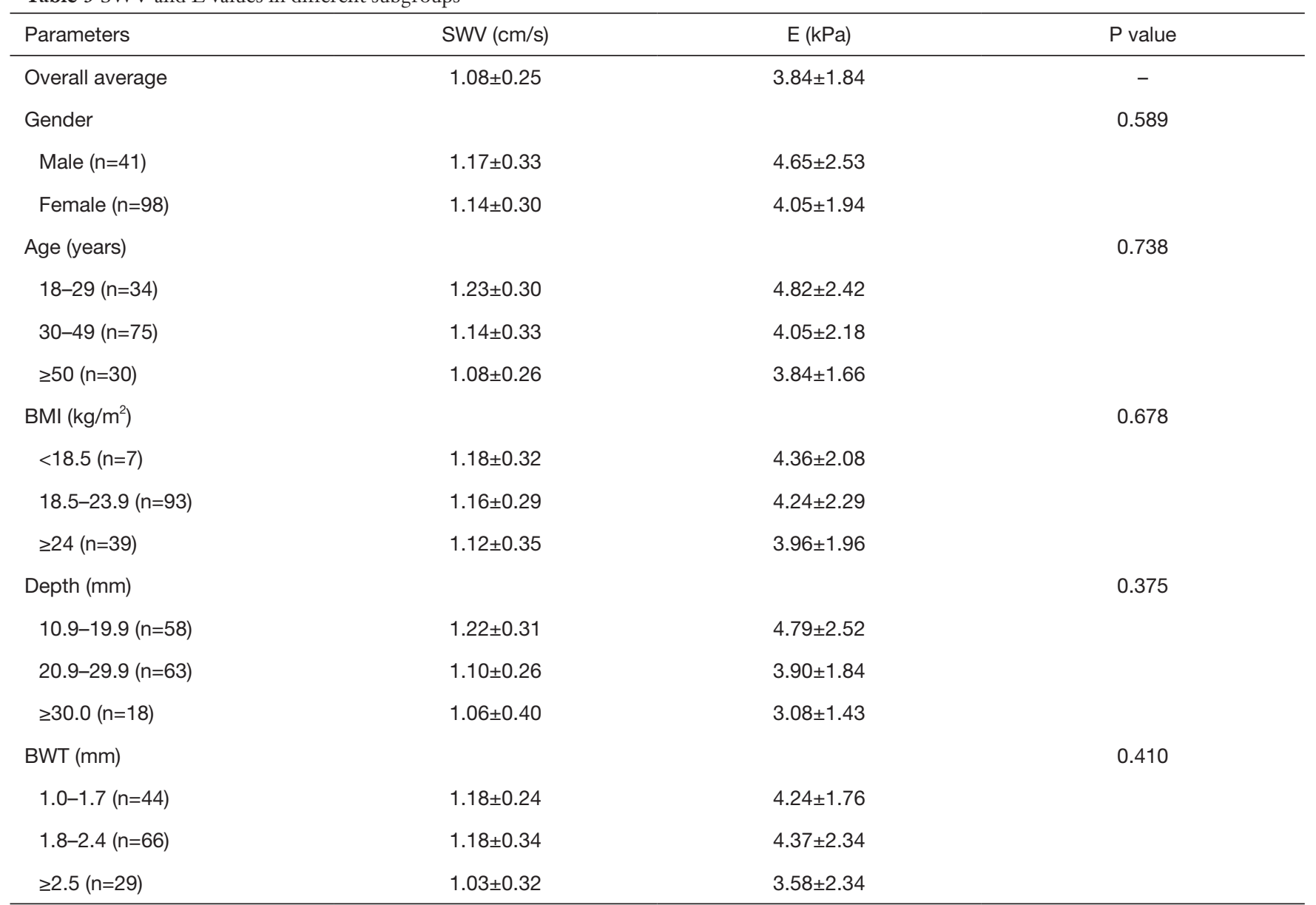

The $\mathrm{P}$ value represents differences in SWV and $\mathrm{E}$ among different subgroups. The $\mathrm{P}$ value of SWV between different genders was calculated by independent $t$-test. One-way analysis of variance was used to calculate the $P$ value of SWV and E among subgroups of age, BMI, depth, and BWT. SWV, shear wave velocity; E, Young's modulus; BMI, body mass index; BWT, bowel wall thickness.

Conventional US is limited in the differential diagnosis of small bowel diseases $(5,27)$. SWE has created substantial interest in the past few years for its ability to provide quantitative tissue elasticity information (30). The underlying principle is that many soft tissues can share similar ultrasonic echogenicity but may have different mechanical properties (3). Studies on the use of SWE in the small intestine are currently scarce (6) and have concentrated on intestinal diseases such as IBD rather than the normal bowel. Inflammation or fibrosis can lead to increases in bowel wall elasticity $(11,14,17,31)$. Average elasticity values in the normal TI conducted with large cohorts have not been listed in the published guidelines and recommendations about the small intestine (32). Therefore, establishing the normal bowel wall's reference ranges is of great value in discriminating between pathological and physiological bowel changes.

In our study, the mean value of SWV in the TI of normal adults was $1.08 \pm 0.25 \mathrm{~m} / \mathrm{s}$, the mean $\mathrm{E}$ was $3.84 \pm 1.84 \mathrm{kPa}$, and the median BWT was $2 \mathrm{~mm}$. Elasticity values were not correlated with other factors (gender, age, BMI, depth, or BWT). Except for gender, BWT was not correlated with other factors (age, BMI, or depth). The E and SWV values in our results did not exactly follow the formula $\mathrm{E}=3 \rho \mathrm{c}^{2}$ due to instrument-related factors. The formula only works under certain limiting assumptions, including neglecting structural stiffness $(3,33)$. The E-value calculated from SWV in our system may deviate. Therefore, SWV provides results that are more closely related to actual stiffness (33).

The main challenges of using SWE in the GI tract include peristalsis, a thin bowel wall, and the presence of gas, contents, etc. Elasticity measurement requires the 
Table 4 BWT of the TI in different subgroups

\begin{tabular}{lll}
\hline Parameters & BWT $(\mathrm{mm})$ & P value \\
\hline Age (years) & & 0.142 \\
$18-29(\mathrm{n}=34)$ & $2.01 \pm 0.52$ & \\
$30-49(\mathrm{n}=75)$ & $2.09 \pm 0.43$ & \\
$\geq 50(\mathrm{n}=30)$ & $2.00 \pm 0.57$ & 0.863 \\
BMI $\left(\mathrm{kg} / \mathrm{m}^{2}\right)$ & \\
$<18.5(\mathrm{n}=7)$ & $1.94 \pm 0.52$ & \\
$18.5-23.9(\mathrm{n}=93)$ & $2.03 \pm 0.47$ & \\
$\geq 24.0(\mathrm{n}=39)$ & $2.17 \pm 0.51$ & 0.368 \\
Depth $(\mathrm{mm})$ & & \\
$10.0-19.9(\mathrm{n}=58)$ & $1.92 \pm 0.43$ & \\
$20.0-29.9(\mathrm{n}=63)$ & $2.15 \pm 0.50$ & \\
$\geq 30.0(\mathrm{n}=18)$ & $2.23 \pm 0.49$ & \\
\hline
\end{tabular}

The $P$ value represents differences in BWT among different subgroups. BMI, body mass index; BWT, bowel wall thickness; $\mathrm{TI}$, terminal ileum.

target to have a stationary anatomic location, minimal peristalsis, and enough BWT to set the ROI. We chose to measure the TI because it met these criteria $(20,29)$, and it is more difficult to make comparisons between healthy and pathological subjects in other segments of the bowel wall.

As previously mentioned, the TI is a preferred location to perform SWE to assess the bowel wall as well as lesions. To our knowledge, there are no published data merely focused on the normal TI. Other relevant studies mostly have other foci, in which reference values of normal TI wall elasticity are involved. For instance, Chen et al. (34) performed a similar study. The average value of $\mathrm{E}$ was $6.38 \pm 1.35 \mathrm{kPa}$ in the normal intestine of healthy volunteers (with a sample size of 59 for the TI), which was higher than that in our study $(3.84 \pm 1.84 \mathrm{kPa})$, and which may be related to the type of US device and the different sample size. A study conducted by Goertz et al. (11) using acoustic radiation force impulse (ARFI) showed that normal SWV values of the TI were $1.6 \pm 0.35 \mathrm{~m} / \mathrm{s}$ (compared with $1.08 \pm 0.25 \mathrm{~m} / \mathrm{s}$ in this study). However, they investigated only 13 healthy volunteers and mainly focused on pathological states.

Our study considers it feasible to utilize SWE in the ileocecal junction for its proper BWT and stationary location. Moreover, the EFSUMB Recommendations and Clinical Guidelines for Intestinal Ultrasound in Inflammatory Bowel Diseases affirmed elastography's value in evaluating the stiffness of a Crohn's stenosis. Several published articles have also confirmed that elastography can stably provide quantitative elasticity information in the IBD bowel wall. Goertz et al. (11) found that the mean ARFI values in an ulcerative colitis group $(1.97 \pm 0.64 \mathrm{~m} / \mathrm{s}$, $\mathrm{n}=20$ ) were higher than those of a healthy control group $(1.75 \pm 0.51 \mathrm{~m} / \mathrm{s}, \mathrm{n}=13)$. Ding et al. (18) indicated that the optimal cut-off value was reached when the shear wave velocity exceeded $2.73 \mathrm{~m} / \mathrm{s}$ in evaluating and differentiating intestinal stenosis in Crohn's disease, with a sensitivity of $75 \%$, a specificity of $100 \%$, and an accuracy of $96 \%$. Another study by Chen et al. (14) suggested using $22.55 \mathrm{kPa}$ as the cut-off $\mathrm{E}$ value in discriminating between mild/moderate and severe fibrosis, and the sensitivity and specificity were $69.6 \%$ and $91.7 \%$ with an area under the curve of 0.822. Despite these findings, relevant research remains inadequate, although research consensus suggests that elasticity is likely to increase in IBD compared with healthy subjects. Based on the current literature, a cut-off value is required to discriminate IBD from the normal bowel wall, and further research efforts are needed in this regard. Compared with studies on IBD, the literature concerning elastography in other GI diseases is scarce.

BWT is by far the most important and popular parameter for Crohn's disease, and many studies have reported the reference values for the bowel wall (TI: $1-3 \mathrm{~mm})(29,35,36)$. We measured the normal value of BWT as a part of our study, and the value $(2 \mathrm{~mm})$ was consistent with previously published guidelines and studies. We used a mid-frequency linear probe $(4-10 \mathrm{MHz})$ to examine the TI since the TI is comparatively superficial. The resolution of a mid-frequency range transducer is quite adequate for separating individual layers in the bowel wall according to the EFSUMB Recommendations and Guidelines for Gastrointestinal Ultrasound (2017) (20). Besides, patients with IBD in China are comparatively thin, without thick abdominal fat. It is not difficult to observe the TI with a mid-high frequency probe in clinical practice.

SWE value measurements can be influenced by several confounders, both technical and patient-related, such as BMI, depth of ROI placement, ROI size, etc. In our study, SWE values did not show any significant difference with BMI. This result was opposite to our expectation, and the reason may be due to unevenly distributed data caused by the lower-than-average BMI in a Chinese population. We were unable to find guidelines defining an inverse or direct correlation between BMI and SWE values, and the results of relevant researches have not been consistent (37). We 
will continue to take note of other reports on the influence of BMI on SWE measurements.

Regarding depth, some studies indicate a decrease of SWV in deeper ROI placements $(38,39)$, while others report no significant correlation (37). In the current literature, SWV measurements appear to be feasible with a depth of placement between $1-5 \mathrm{~cm}(33,38)$. In our study, SWE values did not show any significant difference according to depth. ROI size is also a confounder of SWV measurements. SWV seems to increase with a larger ROI in some studies $(38,39)$, but the trend is not significant in others (40). In this study, we did not analyze SWV in different ROI sizes because the BWT decided the diameter to include the whole bowel wall. Therefore, we did not establish subgroups based on ROI size. The direct correlation between ROI size and SWV measurements in the GI tract should be investigated with a rigorous design in future research. Further studies on a standardized measurement protocol for SWE are required, given the influence of several confounders and the relatively short history of SWE use.

We focused on elasticity values and provided preliminary reference ranges in healthy subjects in a southwest Chinese population. We consider it valuable because of the increasing incidence of IBD worldwide, especially in China (2.8\% annually) (41). The primary data we obtained may be useful in quantitating IBD progression in future studies, especially in assessing the activity and grading of Crohn's disease.

\section{Limitations of the present study}

(I) The volunteers enrolled in our study were asymptomatic and history-free cohorts. Thus we cannot exclude the possibility that some volunteers might have latent diseases.

(II) This is a single-center study using a single vendor (Siemens). We did not compare the differences in SWE values among various US systems.

(III) We chose to measure the anterior TI wall because gas and fecal deposits in the lumen made the posterior wall difficult to see. And our samples of the TI were within $5 \mathrm{~cm}$ of the ileocecal valve, and the reference ranges may not be applicable in other segments of TI.

(IV) Only 20 samples were used to obtain inter and intraoperator consistencies.
(V) The permissible error was set as 0.2 for exploring the preliminary reference ranges. It should be reduced in subsequent studies in order to achieve more precise measurements. This is a pilot study, and the representative elasticity values of the GI tract require further validation.

\section{Conclusions}

The mean value of SWV in the TI of normal adults was $1.08 \pm 0.25 \mathrm{~m} / \mathrm{s}$, the mean $\mathrm{E}$ value was $3.84 \pm 1.84 \mathrm{kPa}$, and the median of BWT was $2 \mathrm{~mm}$. SWE seems to be a promising approach to measure elasticity information of the TI, and SWE values do not appear to vary significantly due to several physiological variables. Future studies are needed with larger cohorts and more rigorous criteria.

\section{Acknowledgments}

Funding: This study was supported by the National Natural Science Foundation of China (grant no. 81101061)

\section{Footnote}

Conflicts of Interest: All authors have completed the ICMJE uniform disclosure form (available at http://dx.doi. org/10.21037/qims-20-877). The authors have no conflicts of interest to declare.

Ethical Statement: The trial was conducted in accordance with the Declaration of Helsinki and the Harmonized Tripartite Guideline for Good Clinical Practice from the International Conference on Harmonization. This study was reviewed and approved by the ethics committee on biomedical research of West China Hospital of Sichuan University (no. 359, 2020). All enrolled patients completed the informed consent form.

Open Access Statement: This is an Open Access article distributed in accordance with the Creative Commons Attribution-NonCommercial-NoDerivs 4.0 International License (CC BY-NC-ND 4.0), which permits the noncommercial replication and distribution of the article with the strict proviso that no changes or edits are made and the original work is properly cited (including links to both the formal publication through the relevant DOI and the license). See: https://creativecommons.org/licenses/by-nc-nd/4.0/. 


\section{References}

1. Ophir J, Cespedes I, Ponnekanti H, Yazdi Y, Li X. Elastography: a quantitative method for imaging the elasticity of biological tissues. Ultrason Imaging 1991;13:111-34.

2. Cosgrove D, Piscaglia F, Bamber J, Bojunga J, Correas JM, Gilja OH, Klauser AS, Sporea I, Calliada F, Cantisani V, D'Onofrio M, Drakonaki EE, Fink M, FriedrichRust M, Fromageau J, Havre RF, Jenssen C, Ohlinger R, Saftoiu A, Schaefer F, Dietrich CF. EFSUMB guidelines and recommendations on the clinical use of ultrasound elastography. Part 2: Clinical applications. Ultraschall Med 2013;34:238-53.

3. Shiina T, Nightingale KR, Palmeri ML, Hall TJ, Bamber JC, Barr RG, Castera L, Choi BI, Chou YH, Cosgrove D, Dietrich CF, Ding H, Amy D, Farrokh A, Ferraioli G, Filice C, Friedrich-Rust M, Nakashima K, Schafer F, Sporea I, Suzuki S, Wilson S, Kudo M. WFUMB guidelines and recommendations for clinical use of ultrasound elastography: Part 1: basic principles and terminology. Ultrasound Med Biol 2015;41:1126-47.

4. Bamber J, Cosgrove D, Dietrich CF, Fromageau J, Bojunga J, Calliada F, Cantisani V, Correas JM, D'Onofrio M, Drakonaki EE, Fink M, Friedrich-Rust M, Gilja OH, Havre RF, Jenssen C, Klauser AS, Ohlinger R, Saftoiu A, Schaefer F, Sporea I, Piscaglia F. EFSUMB guidelines and recommendations on the clinical use of ultrasound elastography. Part 1: Basic principles and technology. Ultraschall Med 2013;34:169-84.

5. Sigrist RMS, Liau J, Kaffas AE, Chammas MC, Willmann JK. Ultrasound Elastography: Review of Techniques and Clinical Applications. Theranostics 2017;7:1303-29.

6. Saftoiu A, Gilja OH, Sidhu PS, Dietrich CF, Cantisani V, Amy D, Bachmann-Nielsen M, Bob F, Bojunga J, Brock M, Calliada F, Clevert DA, Correas JM, D'Onofrio M, Ewertsen C, Farrokh A, Fodor D, Fusaroli P, Havre RF, Hocke M, Ignee A, Jenssen C, Klauser AS, Kollmann C, Radzina M, Ramnarine KV, Sconfienza LM, Solomon C, Sporea I, Stefanescu H, Tanter M, Vilmann P. The EFSUMB Guidelines and Recommendations for the Clinical Practice of Elastography in NonHepatic Applications: Update 2018. Ultraschall Med 2019;40:425-53.

7. Frulio N, Trillaud H. Ultrasound elastography in liver. Diagn Interv Imaging 2013;94:515-34.

8. Magri F, Chytiris S, Chiovato L. The role of elastography in thyroid ultrasonography. Curr Opin Endocrinol
Diabetes Obes 2016;23:416-22.

9. Barr RG, Cosgrove D, Brock M, Cantisani V, Correas JM, Postema AW, Salomon G, Tsutsumi M, Xu HX, Dietrich CF. WFUMB Guidelines and Recommendations on the Clinical Use of Ultrasound Elastography: Part 5. Prostate. Ultrasound Med Biol 2017;43:27-48.

10. Dillman JR, Stidham RW, Higgins PD, Moons DS, Johnson LA, Rubin JM. US elastography-derived shear wave velocity helps distinguish acutely inflamed from fibrotic bowel in a Crohn disease animal model. Radiology 2013;267:757-66.

11. Goertz RS, Lueke C, Schellhaas B, Pfeifer L, Wildner D, Neurath MF, Strobel D. Acoustic radiation force impulse (ARFI) shear wave elastography of the bowel wall in healthy volunteers and in ulcerative colitis. Acta Radiol Open 2019;8:2058460119840969.

12. Chen LD, Wang W, Xu JB, Chen JH, Zhang XH, Wu H, Ye JN, Liu JY, Nie ZQ, Lu MD, Xie XY. Assessment of Rectal Tumors with Shear-Wave Elastography before Surgery: Comparison with Endorectal US. Radiology 2017;285:279-92.

13. Li T, Lu M, Li Y, Li J, Hu Z, Li X, Cheng X, Jiang J, Tan B. Quantitative Elastography of Rectal Lesions: The Value ofShear Wave Elastography in Identifying Benign and Malignant Rectal Lesions. Ultrasound Med Biol 2019;45:85-92.

14. Chen YJ, Mao R, Li XH, Cao QH, Chen ZH, Liu BX, Chen SL, Chen BL, He Y, Zeng ZR, Ben-Horin S, Rimola J, Rieder F, Xie XY, Chen MH. Real-Time Shear Wave Ultrasound Elastography Differentiates Fibrotic from Inflammatory Strictures in Patients with Crohn's Disease. Inflamm Bowel Dis 2018;24:2183-90.

15. Fan Z, Cong Y, Zhang Z, Li R, Wang S, Yan K. Shear Wave Elastography in Rectal Cancer Staging, Compared with Endorectal Ultrasonography and Magnetic Resonance Imaging. Ultrasound Med Biol 2019;45:1586-93.

16. Lu C, Gui X, Chen W, Fung T, Novak K, Wilson SR. Ultrasound Shear Wave Elastography and Contrast Enhancement: Effective Biomarkers in Crohn's Disease Strictures. Inflamm Bowel Dis 2017;23:421-30.

17. Dillman JR, Stidham RW, Higgins PD, Moons DS, Johnson LA, Keshavarzi NR, Rubin JM. Ultrasound shear wave elastography helps discriminate low-grade from high-grade bowel wall fibrosis in ex vivo human intestinal specimens. J Ultrasound Med 2014;33:2115-23.

18. Ding SS, Fang Y, Wan J, Zhao CK, Xiang LH, Liu H, $\mathrm{Pu} \mathrm{H}$, Xu G, Zhang K, Xu XR, Sun XM, Liu C, Wu 
R. Usefulness of Strain Elastography, ARFI Imaging, and Point Shear Wave Elastography for the Assessment of Crohn Disease Strictures. J Ultrasound Med 2019;38:2861-70.

19. Nair A, Liu CH, Singh M, Das S, Le T, Du Y, Soomro S, Aglyamov S, Mohan C, Larin KV. Assessing colitis ex vivo using optical coherence elastography in a murine model. Quant Imaging Med Surg 2019;9:1429-40.

20. Nylund K, Maconi G, Hollerweger A, Ripolles T, Pallotta N, Higginson A, Serra C, Dietrich CF, Sporea I, Saftoiu A, Dirks K, Hausken T, Calabrese E, Romanini L, Maaser C, Nuernberg D, Gilja OH. EFSUMB Recommendations and Guidelines for Gastrointestinal Ultrasound. Ultraschall Med 2017;38:e1-e15.

21. Marin A, Tribus L, Fierbinteanu-Braticevici C. The importance of intestinal ultrasound and elastographic techniques in inflammatory bowel diseases. Med Ultrason 2018;20:228-36.

22. Giannetti A, Matergi M, Biscontri M, Tedone F, Falconi L, Franci L. Real-time elastography in Crohn's disease: feasibility in daily clinical practice. J Ultrasound 2017;20:147-55

23. Garcia-Figueiras R, Baleato-Gonzalez S, Padhani AR, Luna-Alcala A, Marhuenda A, Vilanova JC, OsorioVazquez I, Martinez-de-Alegria A, Gomez-Caamano A. Advanced Imaging Techniques in Evaluation of Colorectal Cancer. Radiographics 2018;38:740-65.

24. Bor R, Fabian A, Szepes Z. Role of ultrasound in colorectal diseases. World J Gastroenterol 2016;22:9477-87.

25. Pescatori LC, Mauri G, Savarino E, Pastorelli L, Vecchi M, Sconfienza LM. Bowel Sonoelastography in Patients with Crohn's Disease: A Systematic Review. Ultrasound Med Biol 2018;44:297-302.

26. Nylund K, Hausken T, Ødegaard S, Eide GE, Gilja $\mathrm{OH}$. Gastrointestinal wall thickness measured with transabdominal ultrasonography and its relationship to demographic factors in healthy subjects. Ultraschall Med 2012;33:E225-E232.

27. Wale A, Pilcher J. Current Role of Ultrasound in Small Bowel Imaging. Semin Ultrasound CT MR 2016;37:301-12.

28. Limberg B. Diagnosis of chronic inflammatory bowel disease by ultrasonography. Z Gastroenterol 1999;37:495-508.

29. Atkinson NSS, Bryant RV, Dong Y, Maaser C, Kucharzik T, Maconi G, Asthana AK, Blaivas M, Goudie A, Gilja OH, Nuernberg D, Schreiber-Dietrich D, Dietrich CF. How to perform gastrointestinal ultrasound: Anatomy and normal findings. World J Gastroenterol 2017;23:6931-41.

30. Nylund K, Odegaard S, Hausken T, Folvik G, Lied GA, Viola I, Hauser H, Gilja OH. Sonography of the small intestine. World J Gastroenterol 2009;15:1319-30.

31. Goertz RS, Lueke C, Wildner D, Vitali F, Neurath MF, Strobel D. Acoustic radiation force impulse (ARFI) elastography of the bowel wall as a possible marker of inflammatory activity in patients with Crohn's disease. Clin Radiol 2018;73:678.e1-678.e5.

32. Lu C, Merrill C, Medellin A, Novak K, Wilson SR. Bowel Ultrasound State of the Art: Grayscale and Doppler Ultrasound, Contrast Enhancement, and Elastography in Crohn Disease. J Ultrasound Med 2019;38:271-88.

33. Tang A, Cloutier G, Szeverenyi NM, Sirlin CB. Ultrasound Elastography and MR Elastography for Assessing Liver Fibrosis: Part 2, Diagnostic Performance, Confounders, and Future Directions. AJR Am J Roentgenol 2015;205:33-40.

34. Chen YJ, Mao R, Liu BX, Xie XH, He Y, Chen MH, Xie XY. Measurement of Stiffness of the Normal lleocolon wall Using Shear Wave Elastography. Chinese Journal of Ultrasound in Medicine 2016;32:343-5

35. Fraquelli M, Colli A, Casazza G, Paggi S, Colucci A, Massironi S, Duca P, Conte D. Role of US in detection of Crohn disease: meta-analysis. Radiology 2005;236:95-101.

36. Maconi G, Nylund K, Ripolles T, Calabrese E, Dirks K, Dietrich CF, Hollerweger A, Sporea I, Saftoiu A, Maaser C, Hausken T, Higginson AP, Nürnberg D, Pallotta N, Romanini L, Serra C, Gilja OH. EFSUMB Recommendations and Clinical Guidelines for Intestinal Ultrasound (GIUS) in Inflammatory Bowel Diseases. Ultraschall Med 2018;39:304-17.

37. Radulescu D, Peride I, Petcu LC, Niculae A, Checherita IA. Supersonic Shear Wave Ultrasonography for Assessing Tissue Stiffness in Native Kidney. Ultrasound Med Biol 2018;44:2556-68.

38. Rominger MB, Kälin P, Mastalerz M, Martini K, Klingmüller V, Sanabria S, Frauenfelder T. Influencing Factors of 2D Shear Wave Elastography of the Muscle - An Ex Vivo Animal Study. Ultrasound Int Open 2018;4:E54-E60.

39. Ruby L, Mutschler T, Martini K, Klingmüller V, Frauenfelder T, Rominger MB, Sanabria SJ. Which Confounders Have the Largest Impact in Shear Wave Elastography of Muscle and How Can They be Minimized? An Elasticity Phantom, Ex Vivo Porcine Muscle and Volunteer Study Using a Commercially Available System. Ultrasound Med Biol 2019;45:2591-611. 
40. Bortolotto C, Lungarotti L, Fiorina I, Zacchino M, Draghi F, Calliada F. Influence of subjects' characteristics and technical variables on muscle stiffness measured by shear wave elastosonography. J Ultrasound 2017;20:139-46.

Cite this article as: Zhao JY, Gao X, Zhuang H, Wu YT, Luo Y, Jing JG, Zhang Y. Using shear wave elasticity in normal terminal ileum of a healthy southwest Chinese population: a pilot study of reference elasticity ranges. Quant Imaging Med Surg 2021;11(6):2677-2687. doi: 10.21037/qims-20-877
41. Fan $Y, L v$ B. Research frontier of inflammatory bowel disease. Zhejiang Da Xue Xue Bao Yi Xue Ban 2019;48:334-41. 